\title{
Ambivalence about Smoking and Cue-Elicited Neural Activity in Quitting-Motivated Smokers Faced with an Opportunity to Smoke
}

\author{
Stephen J. Wilson ${ }^{1}$, Kasey G. Creswell ${ }^{2}$, Michael A. Sayette ${ }^{2,3}$, and Julie A. Fiez ${ }^{2,3}$ \\ ${ }^{1}$ The Pennsylvania State University \\ 2University of Pittsburgh \\ ${ }^{3}$ Center for the Neural Basis of Cognition
}

\section{Abstract}

Many cigarette smokers appear to experience ambivalence about smoking, defined as the simultaneous co-occurrence of a strong desire to smoke and a strong wish to quit smoking. Research suggests that this ambivalence about smoking affects how smokers respond to cigaretterelated stimuli, but many important questions remain about precisely how smoking ambivalence influences cognitive and affective processing during cigarette cue exposure. We used functional magnetic resonance imaging (fMRI) to address this knowledge gap by examining the relation between self-reported ambivalence about smoking and cue-reactivity in quitting-motivated smokers presented with an opportunity to smoke. Eighty-two quitting-motivated cigarette smokers completed a measure assessing their ambivalence about smoking. Subsequently, participants initiated an attempt to quit smoking and underwent an fMRI session, during which they were asked to hold and view a cigarette. Consistent with hypotheses, results indicated that self-reported smoking ambivalence was negatively correlated with cigarette-related activation in brain areas linked to reward-related processing, motivation, and attention (i.e., rostral anterior cingulate and medial prefrontal cortex, caudate nucleus, visual cortex). Self-reported ambivalence was not, however, correlated with activation in brain regions related to conflict processing. This pattern of results is discussed with respect to the process of change for those attempting to quit smoking.

\section{Keywords}

ambivalence; craving; neuroimaging; smoking cue reactivity

\footnotetext{
(C) 2012 Elsevier Ltd. All rights reserved.

Correspondence concerning this article should be addressed to Stephen J. Wilson, Department of Psychology, The Pennsylvania State University, University Park, Pennsylvania 16802. Telephone: (814) 865-6219; Fax: (814) 863-7002; sjw42@ psu.edu.

Contributors

SJW, MAS, and JAF designed the study and wrote the protocol. KGC conducted literature searches and provided summaries of previous research studies. SJW conducted the statistical analysis and wrote the first draft of the manuscript. All authors contributed to and have approved the final manuscript.

Conflict of Interest

All other authors declare that they have no conflicts of interest.

Publisher's Disclaimer: This is a PDF file of an unedited manuscript that has been accepted for publication. As a service to our customers we are providing this early version of the manuscript. The manuscript will undergo copyediting, typesetting, and review of the resulting proof before it is published in its final citable form. Please note that during the production process errors may be discovered which could affect the content, and all legal disclaimers that apply to the journal pertain.
} 
Cigarette smokers exhibit a variety of affective, cognitive, and physiological responses when presented with smoking-related stimuli (Carter \& Tiffany, 1999). The particular pattern of these reactions is thought to depend in large part upon intentions regarding cigarette use (Tiffany, 1990; Wertz \& Sayette, 2001; Wilson, Sayette, \& Fiez, 2004). For heuristic purposes, most theory and research attempting to explicate the effects of smoking intentions on cue-reactivity has employed a broad distinction between smokers with and without an explicit aim to quit smoking. This categorization has proven useful, as findings suggest that smokers who indicate that they do not have plans to stop smoking and those who are actively trying to quit respond differently to cigarette cues in ways that are both conceptually and clinically meaningful (McDermut \& Haaga, 1998; Munoz, Idrissi, Sanchez-Barrera, Fernandez, \& Vila, 2011; Wilson, Sayette, \& Fiez, 2012). For instance, Munoz and colleagues (2011) found that female smokers with high motivation to quit smoking exhibited a stronger startle reflex during exposure to cigarette-related cues than female smokers with low motivation to quit smoking.

Notwithstanding the utility of juxtaposing those with clear intentions to continue or to quit smoking, many smokers exhibit complex motivational states that do not fit neatly into this dichotomy (e.g., Hughes, Keely, Fagerstrom, \& Callas, 2005). In particular, a significant proportion of smokers appear to experience strong ambivalence about smoking, defined as the simultaneous co-occurrence of a strong desire to smoke and a strong wish to quit smoking (Centers for Disease Control and Prevention, 2009; Fong et al., 2004; Stritzke, McEvoy, Wheat, Dyer, \& French, 2007). Further, research suggests that this ambivalence is expressed when smokers are exposed to cigarette cues (Breiner, Stritzke, \& Lang, 1999; Curtin, Barnett, Colby, Rohsenow, \& Monti, 2005; Griffin \& Sayette, 2008). For instance, Breiner and colleagues (1999) found that smokers who were trying to quit simultaneously endorsed strong inclinations to smoke and to avoid doing so when presented with cigaretterelated pictures. More recently, Griffin and Sayette (2008) observed that non-quitting smokers who displayed ambivalent facial expressions (i.e., the concurrent display of expressions related to both positive and negative affect) while holding a lit cigarette had significantly higher scores on self-report measures of smoking ambivalence than did those who did not display ambivalent facial expressions.

Taken together, prior findings suggest that ambivalence about smoking affects responses to cigarette cues and that smokers vary in the degree to which they are ambivalent (Breiner et al., 1999; Griffin \& Sayette, 2008). Little is known, however, about the extent to which specific cognitive and affective reactions to cigarette cues are associated with varying levels of ambivalence. Addressing this knowledge gap may shed important light on the mechanisms that underpin the natural process of change for quitting smokers, as increases in ambivalence about smoking are thought to play a key role in motivating unassisted cessation attempts (Armitage \& Arden, 2007; Lipkus, Green, Feaganes, \& Sedikides, 2001; Lipkus et al., 2005; Stritzke et al., 2007). For example, Lipkus and colleagues (2005) found that selfreported ambivalence about smoking prospectively predicted intentions to quit smoking eight months later in a sample of teenage smokers. Efforts to tease apart the potentially subtle cognitive and affective processes associated with ambivalence using self-report instruments are challenging, as these ratings often require participants to filter their responses through consciousness and impose language on what may be a non-verbal experience. Self-reports thus can be vulnerable to distortions and biases (Nisbett \& Wilson, 1977; Schwarz, 1999). fMRI provides a complementary approach to assessment that permits investigation of diverse mental processes. Developing a better understanding of the links between smoking ambivalence and cue-reactivity also may help to elucidate the active components of smoking cessation interventions, particularly those that attempt to increase the motivation to quit smoking by fostering ambivalence about the behavior (Miller \& Rollnick, 2002). 
Additionally, studying smoking ambivalence as it relates to cue-reactivity has the potential to uncover important information about the nature of drug craving itself. The affect associated with craving often is assumed to be negative (Tiffany, 1992). Emerging research suggests, however, that craving states vary in affective valence, and that episodes of craving can in fact be accompanied by positive affect under certain conditions (Baker, Morse, \& Sherman, 1986; Sayette, 2004; Sayette et al., 2003). It is likely that ambivalence about smoking plays a key role in shaping the affective tone of craving experiences. That is, those who have an unambiguous desire to smoke may be particularly likely to experience a state of craving tinged with positive affect when exposed to cigarette-related cues and an imminent opportunity to smoke. Indeed, smokers may be motivated to "indulge" their urge under such circumstances (Sayette, 2004). In contrast, smokers with a strong ambivalence regarding smoking may be prone to experiencing a state of craving marked by negative affect (e.g., frustration) when faced with cigarettes cues and a chance to smoke (Baker et al., 1986; Sayette, 2004). Examining cue-reactivity in smokers with varying levels of ambivalence therefore may yield insight into the (presumably) different roles that positively and negatively charged craving states play in maintaining cigarette use.

In the present study, we examined the relation between self-reported ambivalence about smoking and cue-reactivity in quitting-motivated smokers presented with an opportunity to smoke. The primary aim of the study was to investigate the degree to which ambivalence about smoking affects appetitive motivational responses to a cigarette cue. We predicted that individuals with low levels of smoking ambivalence (i.e., those with a high desire to smoke during the smoking cue exposure coupled with relatively low momentary interest in abstaining ${ }^{1}$ ) may be motivated to indulge or savor their urge when presented with a cigarette and an imminent opportunity to smoke, as discussed above. Accordingly, we hypothesized that smoking ambivalence would negatively correlate with signals reflecting positive anticipatory processing, such as activation in regions linked to reward-related and motivational functions (i.e., striatum, medial prefrontal cortex [MPFC], and orbitofrontal cortex [OFC]; Franklin et al., 2007; Goldstein \& Volkow, 2002; O'Doherty, 2004) and the allocation of attention (e.g., visual cortical regions; Pessoa \& Engelmann, 2010).

A second objective of the study was to examine whether self-reported ambivalence about smoking was associated with activation in brain areas that play a role in conflict-related processing. While at first glance this may appear to be a straightforward rationale, in fact there are contradictory theories and data associated with the putative link between conflict and ambivalence. In accord with the model advanced by Curtin et al. (2006), one might predict that, to the extent that elevated self-reported ambivalence about smoking engenders subjective discord in the face of cigarette cues and an opportunity to smoke, ambivalence should positively correlate with activation in brain regions supporting the detection of conflict (in particular, the dorsal portion of the anterior cingulate cortex [ACC]; Botvinick, Cohen, \& Carter, 2004; Cunningham, Raye, \& Johnson, 2004) and the deployment of cognitive control (e.g., dorsolateral prefrontal cortex [DLPFC] and ventrolateral prefrontal cortex; Cunningham, Johnson, Gatenby, Gore, \& Banaji, 2003; Kane \& Engle, 2002).

Alternatively, ambivalence about smoking may not be tightly linked to neural activity signifying conflict and its resolution, as research indicates that attitudinal ambivalence is not always associated with subjective dissonance (Newby-Clark, McGregor, \& Zanna, 2002;

\footnotetext{
${ }^{1}$ Our predictions assume that relatively high smoking ambivalence is characterized by a high desire to smoke and a high desire to abstain from smoking, while relatively low smoking ambivalence is characterized by a high desire to smoke and minimal desire to refrain from smoking. Low ambivalence about smoking also, of course, may be associated with a low desire to smoke and a high desire to abstain from smoking. However, given the nature of the sample (i.e., moderate-to-heavy cigarette smokers enrolled prior to the initiation of a quit attempt) and the observation that most participants smoked when given the opportunity to do so (see Wilson et al., 2012, in press), we believe that the aforementioned assumption is valid.
} 
Priester \& Petty, 1996). Moreover, recent findings suggest that ambivalence can moderate responses to appetitive stimuli in reward-related brain areas without concomitantly affecting activity in brain regions implicated in conflict-related processing. Specifically, Frankort and colleagues (Frankort et al., 2011) found that, relative to non-overweight women, overweight women exhibited less activation in several brain areas linked to appetitive motivational processing (e.g., MPFC and OFC) - but did not exhibit elevated activation in areas associated with conflict detection and cognitive control - when viewing pictures of highcalorie palatable foods. The authors proposed that overweight women may have avoided the high-calorie images because of their ambivalence about eating such food, and that this avoidance appeared to be relatively non-effortful (e.g., automatically shifting their gaze from the food cues; see also Werthmann et al., 2011). Given the phenomenological and neurobiological similarities between cue-elicited craving for food and addictive substances (Kassel \& Shiffman, 1992; Volkow \& Wise, 2005), highly ambivalent smokers might exhibit a pattern of neural responses to cigarette cues that is similar to those observed in overweight individuals presented with food stimuli. That is, compared to those with low levels of smoking ambivalence, participants with elevated smoking ambivalence may exhibit dampened activation of reward-related brain regions during cue exposure insofar as they approach such stimuli in a guarded manner; at the same time, smoking ambivalence may be unrelated to activity in conflict- and control-related regions if the processes that result in attenuation of reward-related responses are largely automatic or non-demanding. In other words, in order to experience conflict during cue exposure there needs to be a sufficient level of reward processing. If a participant, due to a desire to quit, has steeled herself to withstand the allure of a smoking cue then there may not be evidence of any conflict. An important feature of the present study is its inclusion of functional magnetic resonance imaging (fMRI), which provided the opportunity to elucidate associations between ambivalence, reward-related processing, and conflict and cognitive control that may be difficult to detect using other methods.

\section{Method}

\section{Participants}

Participants were drawn from two separate fMRI studies. The goal of Study 1 (Wilson et al., 2012) was to examine the effects of quitting motivation and smoking opportunity on neural responses to a smoking cue; the study included both male and females and smokers who were and who were not motivated to quit smoking. The goal of Study 2 (Wilson, Sayette, \& Fiez, in press) was to determine whether different neural mechanisms support self-focused and other-focused coping strategies for coping with a smoking cue coupled with the opportunity to smoke; the study included male smokers who were motivated to quit smoking. For both studies, participants had to report smoking an average of 15 to 40 cigarettes per day for the past 24 months, had to be right-handed, and had to pass an MRI safety screening. In order to identify quitting-motivated participants for enrollment, recruitment materials for both studies solicited inquiries from smokers who were planning on quitting smoking in the near future and who were interested in entering smoking cessation treatment, but did not explicitly offer treatment as a component of the study. We selected only those participants from Study 1 and from Study 2 who reported that they were motivated to quit smoking and who were presented with a smoking cue and an opportunity to smoke during the study. This composite sample included a total of 82 participants ( 25 from Study 1 and 57 from Study 2; 12 female). ${ }^{2}$ As expected, the gender distribution of the sample selected from Study 1 differed significantly from that of Study $2, \lambda^{2}(1, N=82)=$

\footnotetext{
${ }^{2}$ A total of 26 quitting-motivated participants were included in Study 1 (Wilson et al., 2012). One of these participants was not included in the present composite sample because they failed to complete the smoking ambivalence scale.
} 
$32.1 ; \mathrm{p}<.001$. Samples selected from Study 1 and Study 2 did not differ in age, cigarettes per day, years of formal education, or level of nicotine dependence (as assessed with the Fagerstrom Test for Nicotine Dependence [FTND]; Heatherton, Kozlowski, Frecker, \& Fagerstrom, 1991) ( $p$ 's $>0.2$; see Table 1). Written informed consent was obtained from all participants and all procedures were approved by the local Institutional Review Board. Individuals were paid US $\$ 100$ for their participation.

\section{Materials}

Baseline assessment measures-During a baseline assessment, basic demographic information and information regarding smoking patterns were assessed with standard forms (Sayette, Martin, Wertz, Shiffman, \& Perrott, 2001). Participants also completed questionnaires assessing a variety of constructs, including current and past smoking practices, level of nicotine dependence, smoking abstinence self-efficacy, trait self-control, positive and negative affect, and tendency to respond in a socially desirable manner. These data are not a focus of the present study (for additional details, see Wilson et al., 2012).

Smoking ambivalence-Ambivalence about smoking was assessed using a scale developed by Lipkus et al. (2001). Participants rated how strongly they agreed with the following six self-descriptive statements using a scale anchored by 1 (strongly disagree) and 6 (strongly agree): (1) "I have strong feelings both for and against smoking"; (2) "I have conflicting thoughts and feelings about smoking; sometimes I think smoking is good, while at other times I think smoking is bad"; (3) "My gut feeling and my thoughts do not seem to agree on whether I should smoke"; (4) "I find myself feeling torn between wanting and not wanting to smoke"; (5) "My gut feeling about whether to smoke agrees perfectly with what my mind tells me" (reversed scored); and (6) "I have equally strong reasons for wanting and not wanting to smoke." A total score indexing smoking ambivalence was obtained by averaging responses to these items. This scale has demonstrated good internal consistency (see Lipkus et al., 2001; Lipkus et al., 2005) and scores on the measure have been found to correlate with desire to quit smoking (Lipkus et al., 2001; Lipkus et al., 2005) and to predict relapse in those attempting to quit smoking (Menninga, Dijkstra, \& Gebhardt, 2011).

Cue exposure task-Participants completed a cue exposure procedure adapted from prior research (Wilson, Sayette, Delgado, \& Fiez, 2005). Each run of the task began with a 48-s resting baseline epoch during which participants were asked to relax and remain still. After this initial baseline period, an object was placed in the participant's left hand and prerecorded instructions identifying the object were delivered via intercom. Participants were instructed to passively view the object, which they held for a period of $74 \mathrm{~s}$. To allow participants to see what they were holding, a live video feed from a camera focused on their left hand was projected onto a visual display positioned inside the magnet's bore (viewed using a mirror placed above the participants' eyes). Participants completed three runs of the cue exposure task, during which they held a small notepad, a roll of electrical tape, and a cigarette (one of their preferred brand) in the first, second, and third runs, respectively. Upon presentation of the cigarette, a prerecorded message was delivered via intercom informing participants that they would be removed from the scanner in 40 -sec and would be able to smoke immediately if they chose to do so. Participants verbally rated their urge to smoke on a scale from 0 (absolutely no urge to smoke at all) to 100 (strongest urge to smoke I've ever experienced) at the conclusion of the second and third runs of the cue exposure task.

Because there is evidence that exposure to smoking cues affects behavioral and neural responses to subsequently presented items (for review, see Sayette, Griffin, \& Sayers, 2010), the order in which objects were presented was fixed in the aforementioned sequence. The notepad and roll of tape were control objects designed to elicit relatively small changes in 
affect/craving. The first run served as a practice run that allowed participants to acclimate to the task and was excluded from analyses. Before the third run, participants in Study 2 were instructed to utilize the coping strategy that they previously had been trained to use as soon as the cigarette was placed in their hand and to continue doing so until the run concluded. Those in Study 1 were instructed to passively view all objects, including the cigarette.

\section{Procedure}

Participants completed two sessions, which are described in detail elsewhere (see Wilson et al., 2012; Wilson et al., in press). Briefly, for both Study 1 and Study 2, those deemed eligible based upon a telephone screening were scheduled for an initial baseline session during which questionnaires and behavioral working memory assessments were administered. The behavioral working memory assessment consisted of the operation-wordspan task (Turner \& Engle, 1989), the Digit Span subtest of the Wechsler Adult Intelligence Scale-Third Edition (Wechsler, 1997b), and (for Study 1 only) the Spatial Span subtest of the Weschler Memory Scale-Third Edition (Wechsler, 1997a). For Study 2, participants also were trained to use either a self-focused or an other-focused strategy for coping with smoking cue exposure (see Wilson et al., in press). At the conclusion of the session, quitting-motivated smokers were referred for treatment at one of two randomly assigned nocost smoking cessation programs in the community. They telephoned their assigned program to enroll while still in the laboratory. Participants did not receive treatment during the course of the present study and details regarding their utilization of treatment were not collected. Participants then were scheduled for the fMRI-based experimental session (held within two weeks of the baseline session). For all participants included in the present analyses, the experimental session was scheduled to coincide with the first day of an attempt to quit smoking. Specifically, participants were instructed to initiate a cessation attempt $12 \mathrm{hrs}$ before the onset of the experimental visit.

Upon arrival for the experimental session, participants reported the last time they smoked and $\mathrm{CO}$ was measured to check compliance with deprivation instructions. Participants had to have a CO level that was at least 50\% lower than their baseline, a cutoff established based upon research using similar samples and procedures (e.g., Sayette, Loewenstein, Griffin, \& Black, 2008). Participants then verbally rated their urge to smoke on a scale ranging from 0 (absolutely no urge to smoke at all) to 100 (strongest urge to smoke I've ever experienced). Immediately before being placed in the scanner, participants were informed that they would be given a break during the study, at which point they would be given the opportunity to smoke a cigarette. After the collection of anatomical images, participants completed a working memory task (for further details, see Wilson et al., 2012) and then the cue exposure procedure. Additional urge ratings were collected immediately following the second and third runs of the cue exposure task while participants were still holding the tape and cigarette, respectively. Subsequently, participants were removed from the scanner and were presented with the opportunity to smoke. (A total of 66 of the 82 participants included in the present analyses chose to smoke when given the opportunity; those who chose not to smoke were permitted to take a break.) After smoking or taking a break, participants completed post-task questionnaires and were given an opportunity to participate in a follow-up study. Finally, participants were debriefed and paid for their participation.

fMRI data acquisition-Scanning was conducted using a 3-Tesla head-only Siemens Allegra magnet (Siemens Corporation, New York, NY) equipped with a standard transmit/ receive head coil. Prior to functional scanning, a 40 slice oblique-axial anatomical series $(3.125 \times 3.125 \times 3.0 \mathrm{~mm}$ voxels $)$ was acquired parallel to the anterior commissure-posterior commissure plane using a standard T2-weighted pulse sequence. Additionally, a highresolution $(1 \times 1 \times 1 \mathrm{~mm}$ voxels $)$ three-dimensional structural volume was collected using a 
magnetization-prepared rapid gradient-echo sequence. Next, functional images were acquired in the same plane as the 40 -slice anatomical series with coverage limited to the 38 center slices using a one-shot echo-planar imaging pulse sequence $[\mathrm{TR}=2000 \mathrm{~ms}$, TE $=25$ $\mathrm{ms}, \mathrm{FOV}=20 \mathrm{~cm}$, flip angle $\left.=79^{\circ}\right]$. Heart rate was recorded during the acquisition of fMRI data using pulse oximetry from the right middle finger (Invivo 4500 Pulse Oximeter, Invivo Research Inc, Orlando, FL).

fMRI data analysis-Analysis of fMRI data was conducted using utilities from the following software pages: Analysis of Functional NeuroImages (AFNI, Version 2.6; Cox, 1996), Automated Image Registration (AIR, Version 3.08; Woods, Cherry, \& Mazziotta, 1992), FMRIB's Software Library (FSL, Release 4.1; Smith et al., 2004), and the NeuroImaging Software Package (NIS 3.5; Laboratory for Clinical Cognitive Neuroscience, University of Pittsburgh, and the Neuroscience of Cognitive Control Laboratory, Princeton University). Software integration and image format conversion was implemented using the Functional Imaging Software Widgets graphical computing environment (Fissell et al., 2003).

A series of preprocessing steps were employed to correct for artifacts and to account for individual differences in anatomy prior to analyzing fMRI data. Functional images were corrected for head motion and adjusted for drift within and between runs. Anatomical images from each participant were co-registered to a common reference anatomy using a six-parameter rigid-body automated registration algorithm and the transformation matrix generated during this step then was applied to the participant's functional images. Subsequently, functional images were globally mean-normalized and smoothed using a three-dimensional Gaussian filter (4-mm full width at half maximum). Group-based statistical maps were transformed into MNI stereotaxic space (FSL's MNI 152; T1, $1 \times 1 \times$ $1 \mathrm{~mm}$ ) for anatomical localization.

fMRI data were analyzed using a standard two-level random-effects general linear model approach implemented on a voxel-wise (i.e., whole brain) basis. First, a parameter estimate (i.e., beta weight) for activation during the cigarette cue was obtained for each participant. As in our prior work (Wilson et al., 2005), data collected during the final 48-sec of the control and cigarette cue exposure epochs were included in analyses; signal collected during the initial 26-sec of exposure to cues was excluded from the model entirely to allow for stabilization of responses associated with the instructions identifying the object and, for the run in which the cigarette was presented, reminding participants that they would be given the choice to smoke soon. These beta weight estimates were divided by the estimated run baseline to convert them to units of percent change in order to facilitate interpretation and were entered into a second-level regression model (an approach that has been used in several published studies; e.g., see Campbell-Sills et al., 2011; Pagnoni, Zink, Montague, \& Berns, 2002).

As described above, the composite sample used in the present analysis included participants drawn from two separate fMRI studies. Cigarette cue exposure was associated with robust changes in neural activation in each study, as reported elsewhere (Wilson et al., 2012, in press). In order to confirm that cue exposure was associated with comparable effects in the combined sample used herein, we conducted a voxel-wise paired t-test (using AFNI 3dttest) to contrast activation during the presentation of the cigarette cue and control cue. Results from this analysis served as a manipulation check and are presented only briefly.

Our primary aim was to examine the relationship between ambivalence about smoking and neural responses to a cigarette cue in quitting-motivated smokers who were presented with an opportunity to smoke. In order to account for variability associated with coping 
instructions, two dummy code variables were created: self-focused coping $(0=$ not instructed to engage in self-focused coping; $1=$ instructed to engage in self-focused coping) and other-focused coping $(0=$ not instructed to engage in other-focused coping; $1=$ instructed to engage in other-focused coping). ${ }^{3}$ Smoking ambivalence score was entered along with these covariates into a multiple regression model with activation during cigarette cue exposure as the dependent measure. (This analysis, unlike the manipulation check described above, focused only on activation during cigarette cue exposure and did not include activation during the control cue.) This approach allowed us to identify brain areas for which activation during cigarette cue exposure was associated with smoking ambivalence controlling for coping condition.

Based upon Monte Carlo simulations conducted using the AFNI AlphaSim utility, it was determined that a combined per-voxel threshold of $\mathrm{p}<.005$ and cluster-extent threshold of 11 or more contiguous voxels would yield a corrected cluster-wise false positive rate of $p<$. 05. These threshold parameters were applied to the group-based multiple regression statistical map. A slightly more stringent threshold (a per-voxel threshold of $p<.001$ and minimum cluster extent of 11 contiguous voxels) was applied to the statistical map generated by contrasting activation during the cigarette cue and control cue, which proved to be particularly robust.

\section{Results}

\section{Smoking ambivalence ratings}

Participants' mean score on the ambivalence scale was $3.75(S D=0.83)$. Scores ranged from 1.67 to 5.50. Ambivalence scores of participants drawn from Study 1 did not differ significantly from those of participants drawn from Study $2(p>.8)$.

\section{Brain activation during cigarette versus control cue exposure}

Regions exhibiting a main effect of cue are presented in Table 2. Activation was greater during the presentation of the cigarette cue than the control cue in several areas, including the prefrontal cortex, anterior and posterior cingulate, caudate nucleus, thalamus, and cerebellum. Thus, our cue manipulation appears to have been effective. Greater activation during the control cue relative to the cigarette was observed in the superior and middle temporal gyri bilaterally.

\section{Cigarette-related brain activation correlated with smoking ambivalence}

As noted above, our main objective was to characterize the association between ambivalence about smoking and neural activity during cigarette cue exposure in quitting-motivated smokers who were presented with an opportunity to smoke. As summarized in Table 3, significant effects were observed in the rostral ACC and adjacent medial frontal gyrus (MFG), the caudate nucleus and thalamus bilaterally, and the cuneus and lingual gyrus. Ambivalence about smoking was negatively correlated with cigarette-related activation for each of these regions (see Figure 1), suggesting an inverse link between ambivalence and reward processing. There were no significant positive correlations between smoking ambivalence and brain activation during cigarette cue exposure.

In order to assess the specificity of observed associations, we examined the relationship between self-reported smoking ambivalence and brain activation during control cue exposure for the three regions listed above. Smoking ambivalence was not significantly

\footnotetext{
${ }^{3}$ The use of a single dummy code $(0=$ not instructed to cope, $1=$ instructed to cope $)$ yielded nearly identical results. Only results obtained using two dummy code variables are reported.
} 
correlated with activity during presentation of the control cue for any of the brain areas ( $p$ 's $>.1$ ), supporting the idea that ambivalence about smoking was uniquely related to neural responses evoked in the presence of smoking cues and/or an opportunity to smoke.

\section{Discussion}

The overarching goal of this study was to examine the association between self-reported ambivalence about smoking and cue-elicited neural activity in quitting-motivated smokers presented with an opportunity to smoke. One key aim was to test the hypothesis that heightened self-reported smoking ambivalence would be associated with dampened activation of brain regions related to reward-related processing, motivation, and attention. Related to this aim, our major finding was that, consistent with our prediction, smoking ambivalence correlated negatively with the rostral ACC/MFG, dorsal striatum (caudate), and visual cortex (cuneus/lingual gyrus) - regions that have been linked to smoking cuereactivity in several studies (Brody et al., 2004; Brody et al., 2002; Brody et al., 2007; McBride, Barrett, Kelly, Aw, \& Dagher, 2006; McClernon, Hutchison, Rose, \& Kozink, 2007; McClernon, Kozink, Lutz, \& Rose, 2009; McClernon, Kozink, \& Rose, 2008; Okuyemi et al., 2006; Smolka et al., 2006; Wang et al., 2007; Wilson et al., 2005; Wilson et al., 2012). Of these brain areas, drug cue-related activation of the rostral ACC and adjacent MFG has been particularly well-replicated in prior work (Kuhn \& Gallinat, 2011; Wilson et al., 2004).

The precise functions supported by the rostral ACC/MFG remain a matter of debate. Indeed, the region has been linked to a broad set of processes, including the appraisal of value/ salience (Bush, Luu, \& Posner, 2000), emotion regulation (Ochsner \& Gross, 2007), and self-referential processing (Northoff et al., 2006). Notwithstanding the questions that remain about the rostral ACC and MFG, converging evidence indicates that these areas play an important role in affective and motivational processing, including reward-based decisionmaking (Botvinick, 2007; de Greck et al., 2008; Marsh, Blair, Vythilingam, Busis, \& Blair, 2007; Northoff \& Hayes, 2011; Rogers et al., 2004). The current study extends past cue reactivity research by indicating that the magnitude of cue-related activity in the rostral ACC/MFG is modulated by self-reported ambivalence regarding smoking. Our results also complement those obtained in one of the studies from which the present sample was drawn (Wilson et al., 2012). Specifically, we previously found that among those expecting to smoke, quitting-unmotivated and quitting-motivated smokers exhibited opposing patterns of functional connectivity between the rostral ACC/MFG and a region of the prefrontal cortex supporting processes that are critical for goal-directed behavior. Interestingly, findings from our prior study suggested that quitting-unmotivated, but not quitting-motivated, smokers may have engaged in positive anticipatory processing when presented with a cigarette cue and an imminent opportunity to smoke (see Wilson et al., 2012).

The current results point towards a more nuanced picture concerning those who are trying to quit smoking. Specifically, in line with research demonstrating that activation of the rostral PFC/MFG tracks with the magnitude of expected rewards (e.g., Marsh et al., 2007), our findings suggest that like those who are not trying to quit, ostensibly quitting-motivated individuals with low levels of ambivalence about smoking also may engage in rewardrelated processing during cue exposure when cigarettes soon will be accessible (e.g., selffocused attention directed at the positive craving experienced in anticipation of the chance to smoke). In contrast, quitting-motivated smokers with comparatively high levels of ambivalence about smoking appear to be less likely to engage in reward-related processing under such conditions. 
The notion that reward-related responding during cue exposure is influenced by equivocal attitudes towards smoking is further supported by the negative correlation between selfreported smoking ambivalence and activation of the dorsal striatum. The dorsal striatum is critically involved in reward processing and reinforcement-based learning (Delgado, 2007). Of particular relevance, dorsal striatal responses to cues associated with response-contingent rewards increase with the magnitude of the potential reward (Delgado, Locke, Stenger, \& Fiez, 2003; Nieuwenhuis et al., 2005). Further, non-human animal (Ito, Dalley, Robbins, \& Everitt, 2002; See, Elliott, \& Feltenstein, 2007; Vanderschuren, Di Ciano, \& Everitt, 2005) and human brain imaging (Volkow et al., 2006, 2008; Wong et al., 2006) research indicate that the dorsal striatum plays a key role in cued drug-seeking behavior and cue-elicited craving, respectively. The current results suggest that, as ambivalence about smoking grows, smokers may be less likely to engage in the sort of appetitive motivational processes supported by the striatum when cigarette cues and an opportunity to smoke are encountered, and vice versa.

The second key aim of the study was to examine possible associations between self-reported ambivalence and activation of brain regions linked to conflict processing. We did not find significant associations between self-reported ambivalence and cue-related activation in brain areas supporting conflict monitoring and the concomitant implementation of cognitive control, such as the dorsal ACC and DLPFC (Botvinick et al., 2004; Kane \& Engle, 2002;

Kerns et al., 2004; MacDonald, Cohen, Stenger, \& Carter, 2000). While this single null result cannot be taken as strong "evidence of absence," the current findings raise the possibility that verbally expressed smoking ambivalence may not be tightly linked with the degree to which conflict is experienced during tempting situations. As discussed above, smoking ambivalence may be associated with the degree to which smokers protect themselves against or are negatively biased towards cigarette-related stimuli. Accordingly, one explanation is that ambivalence was negatively associated with activation in rewardrelated areas but unrelated to activation in regions associated with conflict and cognitive control, because this negative bias resulted in the use of relatively automatic or unconscious strategies for reducing the response to cues, such as spontaneous shifts of attention away from the cigarette stimulus (cf. Brody et al., 2007; Frankort et al., 2011). Additional research exploring this possibility (in particular, research that incorporates eye-tracking during cue exposure) would be useful.

While ambivalence was not significantly related to neural signals linked to conflict and cognitive control during cue exposure, it is important to note that participants exhibited greater activation in the dorsal ACC and DLPFC when presented with the cigarette than when presented with the control cue. We therefore cannot rule out the possibility that participants were experiencing a high degree of conflict during the study; indeed, we specifically sought to induce such a reaction in those motivated to quit smoking by presenting them with a cigarette and an opportunity to smoke. More broadly, the present data suggest that the construct of conflict may operate at different levels; in some cases the conflict is explicit such that the smoker recognizes both a desire to smoke and to refrain, while in other cases the desire to quit may provide an overarching motivational context that shuts down the desire to smoke altogether, such that conflict-related processes are not affected. More research is needed to elucidate more precisely the relationship between smoking ambivalence and the conflict-related constructs that have been the focus of extensive attention in the cognitive neuroscience literature.

Certain study limitations should be mentioned. The cue exposure protocol that we used consisted of a single presentation of each stimulus over a rather extended period of time. Although this procedure has proven useful for eliciting robust cue reactivity in the scanner (Wilson et al., 2005; Wilson et al., 2012, in press), it may be less sensitive for detecting 
dynamic changes in neural activation (e.g., rapid changes associated with fluctuations in the implementation of cognitive control). In addition, the study relied upon a self-report measure for assessing smoking ambivalence. It may be useful to examine the association between cue-elicited neural activation and other indices of ambivalence about smoking, such as facial reactions during cue exposure (Griffin \& Sayette, 2008). It is also worth noting that smoking ambivalence and cue reactivity were assessed on separate days (during the baseline and experimental session, respectively). It thus is possible that levels of smoking

ambivalence endorsed by participants during the baseline session differed from the degree of ambivalence experienced during cue exposure. Finally, while all participants included in the current study indicated that they were motivated to quit smoking, most chose to smoke a cigarette during the experimental session when presented with an opportunity to do so. As discussed elsewhere (Wilson et al., 2012), unique features of the experimental design may have contributed to the high proportion of ostensibly quitting smokers who chose to smoke a cigarette during the study (e.g., participants could not readily "escape" from the highly tempting opportunity to smoke due to the constraints of MRI environment, as they may do under naturalistic conditions). It is conceivable, however, that participants' motivational state at enrollment may have shifted by the time of the experiment. While this possibility cannot be ruled out, participants endorsed a high level of interest in quitting smoking at the conclusion of the study. Although such data are subject to biases in self-report, they are at least consistent with the idea that participants were in the intended state during the experiment. Further, all quitting-motivated participants accepted a referral to a smoking cessation program, supporting the validity of their self-reported intention to quit.

Notwithstanding these limitations, the use of fMRI allowed for a nuanced investigation of associations among ambivalence, reward responding, and conflict-related processing that may be difficult to achieve via more obtrusive methods, as noted above. Likewise, because the study included a relatively large sample, we were able to extend prior behavioral research and identify self-reported smoking ambivalence as an important moderator of neural responses to cigarette cues. Specifically, smoking ambivalence appears to modulate cue-related responses in brain regions linked to reward-related processing, motivation, and attention, but not areas associated with conflict and cognitive control. Additional investigation of the these effects would provide important data for understanding the nature of smoking craving, as well as the process of change for those attempting to quit smoking.

\section{Acknowledgments}

We thank Deidra Rendinell, Alex Ciuca, and Maryam Khatami for their assistance with data collection and Corrine Durisko, Kate Fissel, Scott Kurdilla, and Deborah Viszlay for technical assistance.

\section{Role of Funding Sources}

Funding for this study was provided by NIDA Grant R01- DA02463. NIDA had no role in the study design, collection, analysis or interpretation of the data, writing the manuscript, or the decision to submit the paper for publication.

\section{References}

Armitage CJ, Arden MA. Felt and potential ambivalence across the stages of change. Journal of Health Psychology. 2007; 12(1):149-158. [PubMed: 17158848]

Baker, TB.; Morse, E.; Sherman, JE. The motivation to use drugs: a psychobiological analysis of urges. In: Rivers, C., editor. The Nebraska Symposium on Motivation: Alchol use and abuse. Vol. 34. Lincoln: University of Nebraska Press; 1986. p. 257-323.

Botvinick MM. Conflict monitoring and decision making: reconciling two perspectives on anterior cingulate function. Cognitive, Affective and Behavioral Neuroscience. 2007; 7(4):356-366. 
Botvinick MM, Cohen JD, Carter CS. Conflict monitoring and anterior cingulate cortex: an update. Trends Cogn Sci. 2004; 8(12):539-546. [PubMed: 15556023]

Breiner MJ, Stritzke WG, Lang AR. Approaching avoidance. A step essential to the understanding of craving. Alcohol Research and Health. 1999; 23(3):197-206. [PubMed: 10890815]

Brody AL, Mandelkern MA, Lee G, Smith E, Sadeghi M, Saxena S, London ED, et al. Attenuation of cue-induced cigarette craving and anterior cingulate cortex activation in bupropion-treated smokers: a preliminary study. Psychiatry Research. 2004; 130(3):269-281. [PubMed: 15135160]

Brody AL, Mandelkern MA, London ED, Childress AR, Lee GS, Bota RG, Jarvik ME, et al. Brain metabolic changes during cigarette craving. Archives of General Psychiatry. 2002; 59(12):11621172. [PubMed: 12470133]

Brody AL, Mandelkern MA, Olmstead RE, Jou J, Tiongson E, Allen V, Cohen MS, et al. Neural substrates of resisting craving during cigarette cue exposure. Biological Psychiatry. 2007; 62(6): 642-651. [PubMed: 17217932]

Bush G, Luu P, Posner MI. Cognitive and emotional influences in anterior cingulate cortex. Trends Cogn Sci. 2000; 4(6):215-222. [PubMed: 10827444]

Campbell-Sills L, Simmons AN, Lovero KL, Rochlin AA, Paulus MP, Stein MB. Functioning of neural systems supporting emotion regulation in anxiety-prone individuals. Neuroimage. 2011; 54(1):689-696. [PubMed: 20673804]

Carter BL, Tiffany ST. Meta-analysis of cue-reactivity in addiction research. Addiction. 1999; 94(3): 327-340. [PubMed: 10605857]

Centers for Disease Control and Prevention. Cigarette smoking among adults and trends in smoking cessation - United States, 2008. MMWR; Morbidity and Mortality Weekly Report. 2009; 58(44): 1227-1232.

Cox RW. AFNI: software for analysis and visualization of functional resonance neuroimages. Computational and Biomedical Research. 1996; 29:162-173.

Cunningham WA, Johnson MK, Gatenby JC, Gore JC, Banaji MR. Neural components of social evaluation. Journal of Personality and Social Psychology. 2003; 85(4):639-649. [PubMed: 14561118]

Cunningham WA, Raye CL, Johnson MK. Implicit and explicit evaluation: FMRI correlates of valence, emotional intensity, and control in the processing of attitudes. Journal of Cognitive Neuroscience. 2004; 16(10):1717-1729. [PubMed: 15701224]

Curtin JJ, Barnett NP, Colby SM, Rohsenow DJ, Monti PM. Cue reactivity in adolescents: measurement of separate approach and avoidance reactions. Journal of Studies on Alcohol. 2005; 66(3):332-343. [PubMed: 16047522]

Curtin, JJ.; McCarthy, DE.; Piper, ME.; Baker, TB. Implicit and Explicit Drug Motivational Processes: A Model of Boundary Conditions. In: Wiers, Reinout W.; Stacy, Alan W., editors. Handbook of implicit cognition and addiction. Thousand Oaks, CA US: Sage Publications, Inc. 2549; 2006. p. 2233-2250.

de Greck M, Rotte M, Paus R, Moritz D, Thiemann R, Proesch U, Northoff G, et al. Is our self based on reward? Self-relatedness recruits neural activity in the reward system. Neuroimage. 2008; 39(4):2066-2075. [PubMed: 18155927]

Delgado MR. Reward-related responses in the human striatum. Annals of the New York Academy of Sciences. 2007; 1104:70-88. [PubMed: 17344522]

Delgado MR, Locke HM, Stenger VA, Fiez JA. Dorsal striatum responses to reward and punishment: effects of valence and magnitude manipulations. Cognitive, Affective and Behavioral Neuroscience. 2003; 3(1):27-38.

Fissell C, Tseytlin E, Cunningham D, Iyer K, Carter CS, Schneider W, Cohen JD. A graphical computing environment for neuroimaging analysis. Neuroinformatics. 2003; 1:111-125. [PubMed: 15055396]

Fong GT, Hammond D, Laux FL, Zanna MP, Cummings KM, Borland R, Ross H. The near-universal experience of regret among smokers in four countries: findings from the International Tobacco Control Policy Evaluation Survey. Nicotine and Tobacco Research. 2004; 6(Suppl 3):S341-351. [PubMed: 15799597] 
Franklin TR, Wang Z, Wang J, Sciortino N, Harper D, Li Y, Childress AR, et al. Limbic activation to cigarette smoking cues independent of nicotine withdrawal: a perfusion fMRI study. Neuropsychopharmacology. 2007; 32(11):2301-2309. [PubMed: 17375140]

Frankort A, Roefs A, Siep N, Roebroeck A, Havermans R, Jansen A. Reward activity in satiated overweight women is decreased during unbiased viewing but increased when imagining taste: an event-related fMRI study. International Journal of Obesity. 2011

Goldstein RZ, Volkow ND. Drug addiction and its underlying neurobiological basis: neuroimaging evidence for the involvement of the frontal cortex. American Journal of Psychiatry. 2002; 159(10): 1642-1652. [PubMed: 12359667]

Griffin KM, Sayette MA. Facial reactions to smoking cues relate to ambivalence about smoking. Psychology of Addictive Behaviors. 2008; 22(4):551-556. [PubMed: 19071980]

Heatherton TF, Kozlowski LT, Frecker RC, Fagerstrom KO. The Fagerstrom Test for Nicotine Dependence: a revision of the Fagerstrom Tolerance Questionnaire. British Journal of Addiction. 1991; 86(9):1119-1127. [PubMed: 1932883]

Hughes JR, Keely JP, Fagerstrom KO, Callas PW. Intentions to quit smoking change over short periods of time. Addictive Behaviors. 2005; 30(4):653-662. [PubMed: 15833571]

Ito R, Dalley JW, Robbins TW, Everitt BJ. Dopamine release in the dorsal striatum during cocaineseeking behavior under the control of a drug-associated cue. Journal of Neuroscience. 2002; 22(14):6247-6253. [PubMed: 12122083]

Kane MJ, Engle RW. The role of prefrontal cortex in working-memory capacity, executive attention, and general fluid intelligence: An individual-differences perspective. Psychonomic Bulletin and Review. 2002; 9(4):637-671. [PubMed: 12613671]

Kassel JD, Shiffman S. What can hunger teach us about drug craving? A comparative analysis of the two constructs. Advances in Behaviour Research and Therapy. 1992; 14(3):141-167.

Kerns JG, Cohen JD, MacDonald AW 3rd, Cho RY, Stenger VA, Carter CS. Anterior cingulate conflict monitoring and adjustments in control. Science. 2004; 303(5660):1023-1026. [PubMed: 14963333]

Kuhn S, Gallinat J. Common biology of craving across legal and illegal drugs - a quantitative metaanalysis of cue-reactivity brain response. European Journal of Neuroscience. 2011; 33(7):13181326. [PubMed: 21261758]

Lipkus IM, Green JD, Feaganes JR, Sedikides C. The relationship between attitudinal ambivalence and desire to quit smoking among college smokers. Journal of Applied Social Psychology. 2001; 31(1):113-133.

Lipkus IM, Pollack KI, McBride CM, Schwartz-Bloom R, Lyna P, Bloom PN. Assessing attitudinal ambivalence towards smoking and its association with desire to quit among teen smokers. Psychology and Health. 2005; 20(3):373-387.

MacDonald AW 3rd, Cohen JD, Stenger VA, Carter CS. Dissociating the role of the dorsolateral prefrontal and anterior cingulate cortex in cognitive control. Science. 2000; 288(5472):1835-1838. [PubMed: 10846167]

Marsh AA, Blair KS, Vythilingam M, Busis S, Blair RJ. Response options and expectations of reward in decision-making: the differential roles of dorsal and rostral anterior cingulate cortex. Neuroimage. 2007; 35(2):979-988. [PubMed: 17292631]

McBride D, Barrett SP, Kelly JT, Aw A, Dagher A. Effects of expectancy and abstinence on the neural response to smoking cues in cigarette smokers: an fMRI study. Neuropsychopharmacology. 2006; 31(12):2728-2738. [PubMed: 16598192]

McClernon FJ, Hutchison KE, Rose JE, Kozink RV. DRD4 VNTR polymorphism is associated with transient fMRI-BOLD responses to smoking cues. Psychopharmacology. 2007; 194(4):433-441. [PubMed: 17611740]

McClernon FJ, Kozink RV, Lutz AM, Rose JE. 24-h smoking abstinence potentiates fMRI-BOLD activation to smoking cues in cerebral cortex and dorsal striatum. Psychopharmacology. 2009; 204(1):25-35. [PubMed: 19107465]

McClernon FJ, Kozink RV, Rose JE. Individual differences in nicotine dependence, withdrawal symptoms, and sex predict transient fMRI-BOLD responses to smoking cues. Neuropsychopharmacology. 2008; 33(9):2148-2157. [PubMed: 17987060] 
McDermut W, Haaga DA. Effect of stage of change on cue reactivity in continuing smokers. Experimental and Clinical Psychopharmacology. 1998; 6(3):316-324. [PubMed: 9725115]

Menninga KM, Dijkstra A, Gebhardt WA. Mixed feelings: Ambivalence as a predictor of relapse in ex-smokers. Br J Health Psychol. 2011; 16(3):580-591. [PubMed: 21722277]

Miller, WR.; Rollnick, S. Motivational interviewing: Preparing people to change addictive behavior. 2. New York, NY: Guilford Press; 2002.

Munoz MA, Idrissi S, Sanchez-Barrera MB, Fernandez MC, Vila J. Motivation to quit smoking and startle modulation in female smokers: context specificity of smoking cue reactivity.

Psychopharmacology. 2011

Newby-Clark IR, McGregor I, Zanna MP. Thinking and caring about cognitive inconsistency: when and for whom does attitudinal ambivalence feel uncomfortable? Journal of Personality and Social Psychology. 2002; 82(2):157-166. [PubMed: 11831406]

Nieuwenhuis S, Heslenfeld DJ, von Geusau NJ, Mars RB, Holroyd CB, Yeung N. Activity in human reward-sensitive brain areas is strongly context dependent. Neuroimage. 2005; 25(4):1302-1309. [PubMed: 15945130]

Nisbett RE, Wilson TD. Telling more than we can know: Verbal reports on mental processes. Psychological Review. 1977; 84(3):231-259.

Northoff G, Hayes DJ. Is our self nothing but reward? Biological Psychiatry. 2011; 69(11):1019-1025. [PubMed: 21276963]

Northoff G, Heinzel A, de Greck M, Bermpohl F, Dobrowolny H, Panksepp J. Self-referential processing in our brain--a meta-analysis of imaging studies on the self. Neuroimage. 2006; 31(1): 440-457. [PubMed: 16466680]

O'Doherty JP. Reward representations and reward-related learning in the human brain: insights from neuroimaging. Current Opinion in Neurobiology. 2004; 14(6):769-776. [PubMed: 15582382]

Ochsner, KN.; Gross, JJ. The neural architecture of emotion regulation. In: Gross, JJ., editor. Handbook of emotion regulation. New York, NY: Guilford Press; 2007. p. 87-109.

Okuyemi KS, Powell JN, Savage CR, Hall SB, Nollen N, Holsen LM, Ahluwalia JS, et al. Enhanced cue-elicited brain activation in African American compared with Caucasian smokers: an fMRI study. Addiction Biology. 2006; 11(1):97-106. [PubMed: 16759342]

Pagnoni G, Zink CF, Montague PR, Berns GS. Activity in human ventral striatum locked to errors of reward prediction. Nature Neuroscience. 2002; 5(2):97-98.

Pessoa L, Engelmann JB. Embedding reward signals into perception and cognition. Frontiers in Neuroscience. 2010; 4

Priester JR, Petty RE. The gradual threshold model of ambivalence: relating the positive and negative bases of attitudes to subjective ambivalence. Journal of Personality and Social Psychology. 1996; 71(3):431-449. [PubMed: 8831157]

Rogers RD, Ramnani N, Mackay C, Wilson JL, Jezzard P, Carter CS, Smith SM. Distinct portions of anterior cingulate cortex and medial prefrontal cortex are activated by reward processing in separable phases of decision-making cognition. Biological Psychiatry. 2004; 55(6):594-602. [PubMed: 15013828]

Sayette, MA. Self-regulatory failure and addiction. In: Baumeister, RF.; Vohs, KD., editors. Handbook of self-regulation: Research, theory, and applications. New York: Guilford Press; 2004. p. 447-465.

Sayette MA, Griffin KM, Sayers WM. Counterbalancing in smoking cue research: A critical analysis. Nicotine and Tobacco Research. 2010; 12(11):1068-1079. [PubMed: 20884695]

Sayette MA, Loewenstein G, Griffin KM, Black JJ. Exploring the cold-to-hot empathy gap in smokers. Psychological Science. 2008; 19(9):926-932. [PubMed: 18947359]

Sayette MA, Martin CS, Wertz JM, Shiffman S, Perrott MA. A multi-dimensional analysis of cueelicited craving in heavy smokers and tobacco chippers. Addiction. 2001; 96(10):1419-1432. [PubMed: 11571061]

Sayette MA, Wertz JA, Martin CS, Cohn JF, Perrott MA, Hobel J. Effects of smoking opportunity on cue-elicited urge: A facial coding analysis. Experimental and Clinical Psychopharmacology. 2003; 11(3):218-227. [PubMed: 12940501] 
Schwarz N. Self-reports: How the questions shape the answers. American Psychologist. 1999; 54(2): 93-105.

See RE, Elliott JC, Feltenstein MW. The role of dorsal vs ventral striatal pathways in cocaine-seeking behavior after prolonged abstinence in rats. Psychopharmacology. 2007; 194(3):321-331. [PubMed: 17589830]

Smith SM, Jenkinson M, Woolrich MW, Beckmann CF, Behrens TE, Johansen-Berg H, Matthews $\mathrm{PM}$, et al. Advances in functional and structural MR image analysis and implementation as FSL. Neuroimage. 2004; 23(Suppl 1):S208-219. [PubMed: 15501092]

Smolka MN, Buhler M, Klein S, Zimmermann U, Mann K, Heinz A, Braus DF. Severity of nicotine dependence modulates cue-induced brain activity in regions involved in motor preparation and imagery. Psychopharmacology. 2006; 184(3-4):577-588. [PubMed: 16133128]

Stritzke, WG.; McEvoy, PM.; Wheat, LR.; Dyer, KR.; French, DJ. The Yin and Yang of Indulgence and Restraint: The Ambivalence Model of Craving. In: O’Neal, PW., editor. Motivation of Health Behavior. New York: Nova Science Publishers; 2007. p. 31-47.

Tiffany ST. A cognitive model of drug urges and drug-use behavior: role of automatic and nonautomatic processes. Psychological Review. 1990; 97(2):147-168. [PubMed: 2186423]

Tiffany ST. A critique of contemporary urge and craving research: Methodological, psychometric, and theoretical issue. Advances in Behaviour Research and Therapy. 1992; 14:123-139.

Turner ML, Engle RW. Is working memory capacity task dependent? Journal of Memory \& Language. 1989; 28(2):127-154.

Vanderschuren LJ, Di Ciano P, Everitt BJ. Involvement of the dorsal striatum in cue-controlled cocaine seeking. Journal of Neuroscience. 2005; 25(38):8665-8670. [PubMed: 16177034]

Volkow ND, Wang GJ, Telang F, Fowler JS, Logan J, Childress AR, Wong C, et al. Cocaine cues and dopamine in dorsal striatum: mechanism of craving in cocaine addiction. Journal of Neuroscience. 2006; 26(24):6583-6588. [PubMed: 16775146]

Volkow ND, Wang GJ, Telang F, Fowler JS, Logan J, Childress AR, Wong C, et al. Dopamine increases in striatum do not elicit craving in cocaine abusers unless they are coupled with cocaine cues. Neuroimage. 2008; 39(3):1266-1273. [PubMed: 18024160]

Volkow ND, Wise RA. How can drug addiction help us understand obesity? Nature Neuroscience. 2005; 8(5):555-560.

Wang Z, Faith M, Patterson F, Tang K, Kerrin K, Wileyto EP, Lerman C, et al. Neural substrates of abstinence-induced cigarette cravings in chronic smokers. Journal of Neuroscience. 2007; 27(51): 14035-14040. [PubMed: 18094242]

Wechsler, D. Wechsler Memory Scale - Third Edition: Administration and scoring manual. San Antonio, TX: The Psychological Corporation; 1997a.

Wechsler, D. WechslerAdult Intelligence Scale - Third Edition: Administration and scoring manual. San Antonio, TX: The Psychological Corporation; 1997b.

Werthmann J, Roefs A, Nederkoorn C, Mogg K, Bradley BP, Jansen A. Can(not) take my eyes off it: attention bias for food in overweight participants. Health Psychology. 2011; 30(5):561-569. [PubMed: 21767019]

Wertz JM, Sayette MA. A review of the effects of perceived drug use opportunity on self-reported urge. Experimental and Clinical Psychopharmacology. 2001; 9(1):3-13. [PubMed: 11519632]

Wilson SJ, Sayette MA, Delgado MR, Fiez JA. Instructed smoking expectancy modulates cue-elicited neural activity: A preliminary study. Nicotine and Tobacco Research. 2005; 7(4):637-645. [PubMed: 16085533]

Wilson SJ, Sayette MA, Fiez JA. Prefrontal responses to drug cues: a neurocognitive analysis. Nature Neuroscience. 2004; 7(3):211-214.

Wilson SJ, Sayette MA, Fiez JA. Quitting-unmotivated and quitting-motivated cigarette smokers exhibit different patterns of cue-elicited brain activation when anticipating an opportunity to smoke. Journal of Abnormal Psychology. 2012; 121(1):198-211. [PubMed: 21859165]

Wilson SJ, Sayette MA, Fiez JA. Self-Focused versus other-focused strategies for coping with smoking cue exposure: A functional magnetic resonance imaging study. Psychology of Addictive Behaviors. in press. 
Wong DF, Kuwabara H, Schretlen DJ, Bonson KR, Zhou Y, Nandi A, London ED, et al. Increased occupancy of dopamine receptors in human striatum during cue-elicited cocaine craving. Neuropsychopharmacology. 2006; 31(12):2716-2727. [PubMed: 16971900]

Woods R, Cherry S, Mazziotta J. Rapid automated algorithm for aligning and reslicing PET images. Journal of Computer Assisted Tomography. 1992; 16:620-633. [PubMed: 1629424] 


\section{Highlights}

- Quitting-motivated smokers were presented with a cigarette and a chance to smoke

- We examined the relation between smoking ambivalence cue-elicited brain activation

- Ambivalence negatively correlated with activation in areas linked to motivation

- Ambivalence was not correlated with activation in regions related to conflict 
a
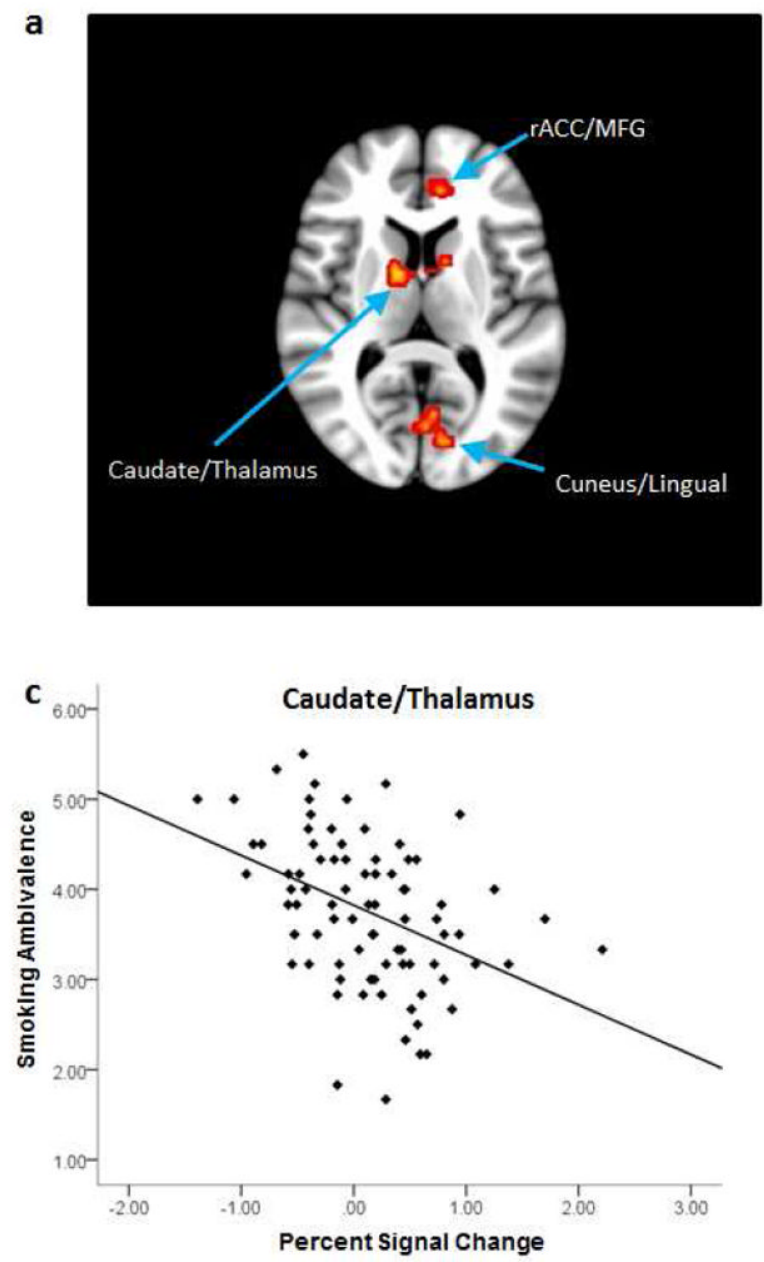

b

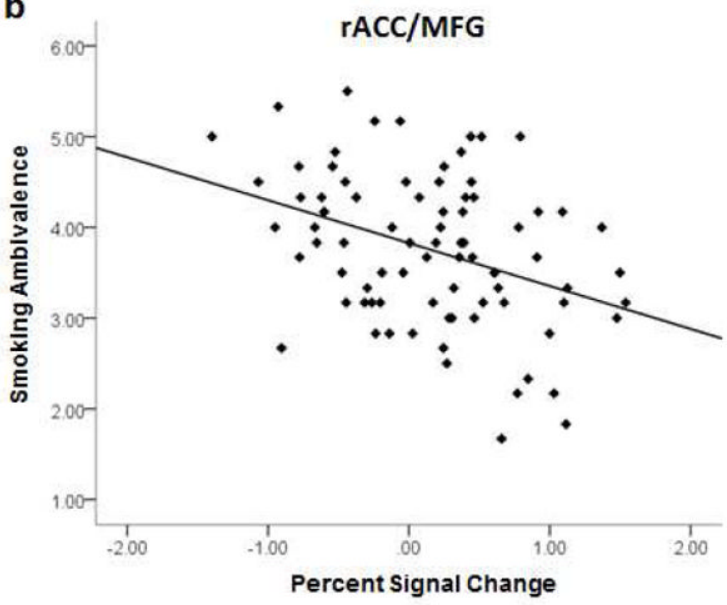

d

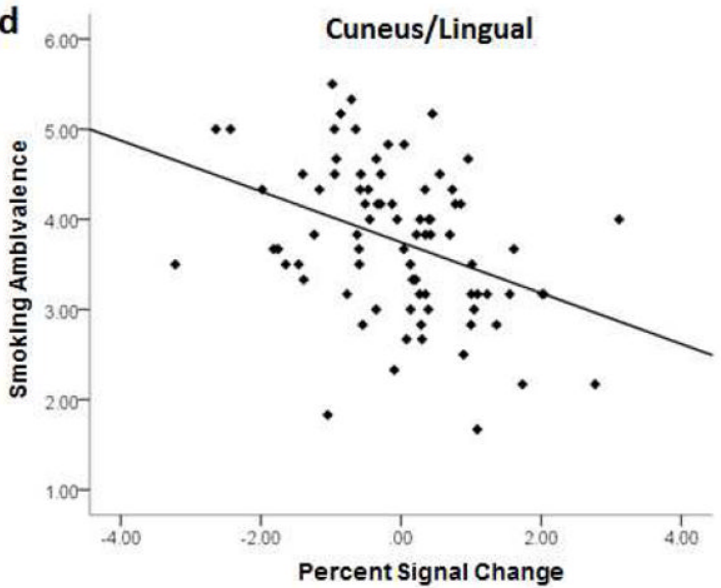

Figure 1.

Cigarette-related brain activation associated with ambivalence about smoking (a). Brain slice is nine millimeters above the anterior commissure-posterior commissure plane in MNI stereotaxic space and is right-left reversed. Scatter plots depict the correlation between ambivalence about smoking and activation during cigarette cue exposure in (b) the rostral anterior cingulate/medial frontal gyrus, (c) caudate nucleus/thalamus, and (d) cuneus/lingual gyrus. 


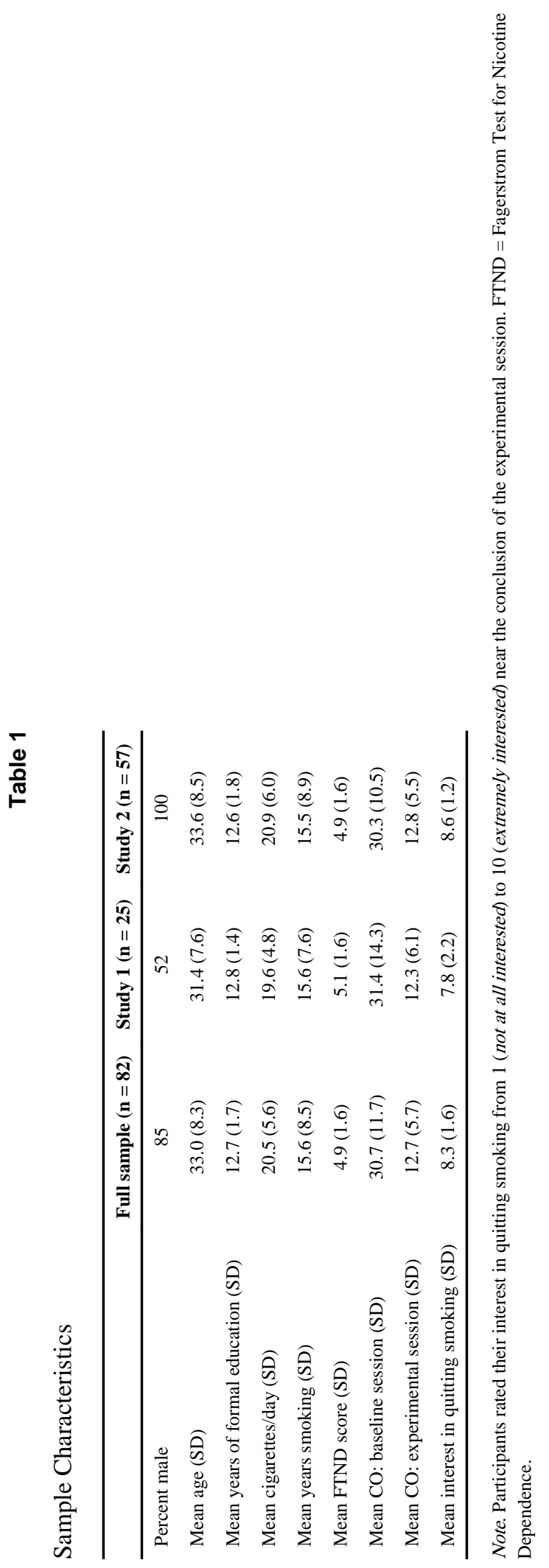



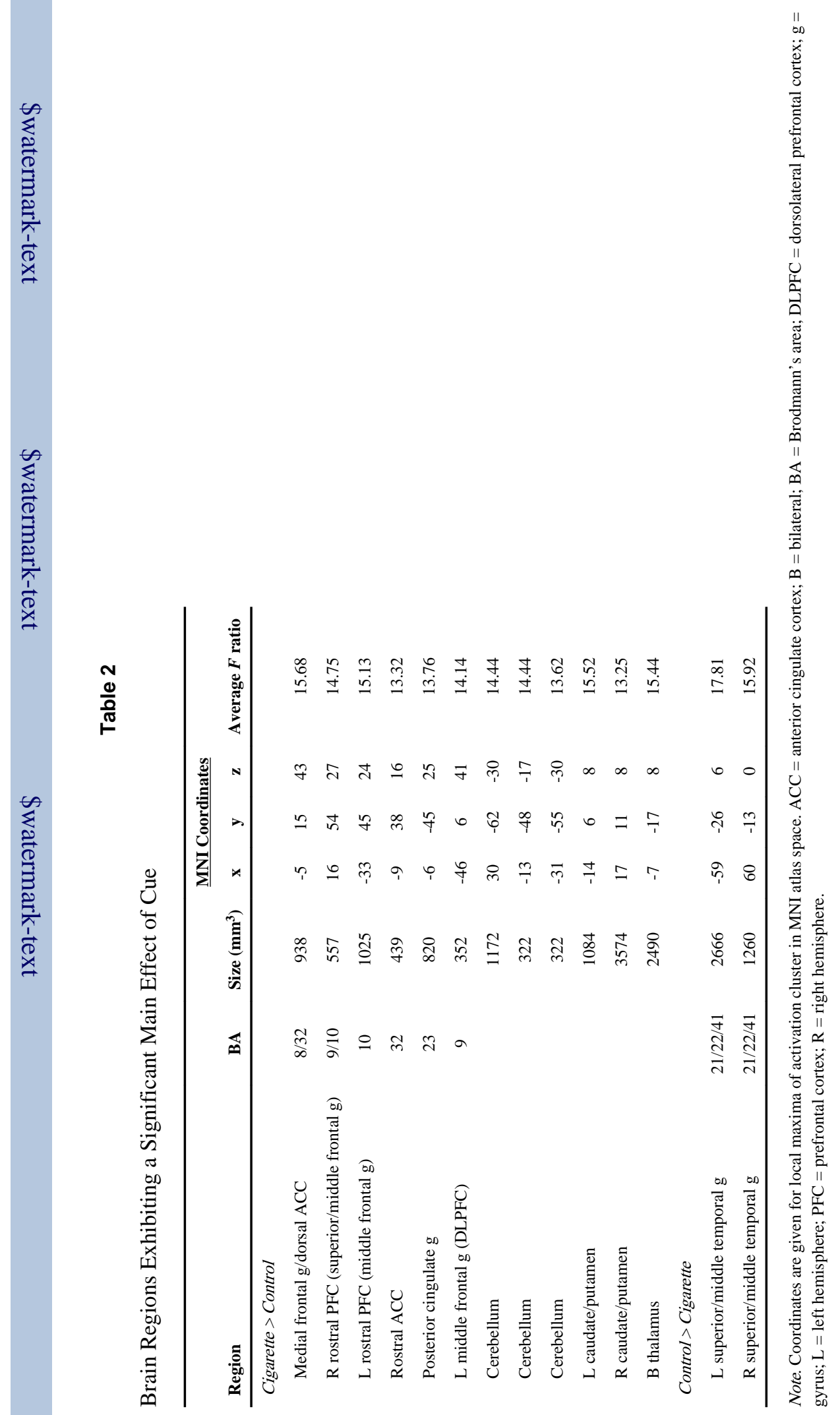

Addict Behav. Author manuscript; available in PMC 2014 February 01. 
